\title{
Prevalence and characteristics of incidental colorectal polyps in patients undergoing colonoscopy at a South African tertiary institution
}

\author{
J Kruger, ${ }^{1} \mathrm{MB}$ ChB; L Katsidzira, ${ }^{2} \mathrm{MB}$ ChB, MMed (Int Med), Cert Gastroenterology (SA); M Setshedi, ${ }^{3} \mathrm{MB}$ ChB, FCP (SA), \\ Cert Gastroenterology (SA), MPH, PhD; S R Thomson, ${ }^{3}$ ChM, FRCS (Eng and Ed), FRCP (Ed) \\ 'Department of Medicine, Faculty of Health Sciences, Groote Schuur Hospital and University of Cape Town, South Africa \\ ${ }^{2}$ Department of Medicine, College of Health Sciences, University of Zimbabwe, Harare, Zimbabwe \\ Division of Gastroenterology, Department of Medicine, Faculty of Health Sciences, Groote Schuur Hospital and University of Cape Town, \\ South Africa
}

Corresponding author: J Kruger (jeanjacqueskruger@gmail.com)

\begin{abstract}
Background. There is a lack of data on the frequency and pattern of colorectal adenomas in sub-Saharan Africa to guide diagnostic and preventive strategies for colorectal cancer (CRC) in the region.

Objectives. To describe polyp characteristics and adenoma frequency in patients at average risk of CRC, who are undergoing colonoscopy for bowel symptoms at a tertiary hospital in South Africa (SA).

Methods. Colonoscopy records from the prospective endoscopy database at Groote Schuur Hospital, Cape Town, SA, from August 2014 to February 2017, were retrieved. The presence of polyps, and their morphology, size, site and number in relation to ethnicity, symptoms and colonoscopy quality indicators were analysed. The histological type and grade were obtained from laboratory records and analysed. The primary endpoint was the adenoma detection rate (ADR). Age, gender, ethnicity, symptoms, bowel preparation and caecal intubation rates were also compared between patients with adenomas and those without.

Results. Of 1334 colonoscopies, 342 were performed in patients at increased risk of premalignant lesions; these were excluded from the analysis. Polyps were identified in 172 of the remaining 992 patients (17.3\%), whose self-declared ethnicity was mixed race (76\%), white (12\%), black African (11\%) or Asian (1\%). The quality of bowel preparation and caecal intubation rate were similar between patients with polyps and those without. Patients with polyps were older than those without polyps (mean age 61.5 (standard deviation 12.9) v. 56.3 (17.4) years; $p<0.002)$. On histological examination of these polyps, 119 were adenomas, 26 were hyperplastic and 27 were normal. The majority of the adenomas were tubular $(80 \%)$, and there were only $6 \%$ with high-grade dysplasia. Half $(51 \%)$ of the adenomas were in the proximal colon, and the overall ADR was 12\%. The ADR (prevalence) was highest in white and Asian South Africans (18\% each), followed by that in persons of mixed race (13\%), but much lower in black Africans (5\%).

Conclusions. This study provides a benchmark ADR for our catchment population and potentially across Africa. There is evidence of a continuing differential colorectal neoplasia risk according to ethnicity, with fewer adenomas being detected in black South Africans.
\end{abstract}

S Afr Med J 2020;110(12):1191-1194. https://doi.org/10.7196/SAMJ.2020.v110i12.14582

Colorectal cancer (CRC) is the second most common cancer in women, and the third most common in men, and accounts for $10 \%$ of all cancers worldwide..$^{[1]}$ Classically, CRCs arise from adenomas, through the adenoma-carcinoma sequence described by Fearon and Vogelstein. ${ }^{[2]}$ The prevalence of adenomas in a population generally correlates with the incidence of CRC. The latter varies widely across the globe, with the USA and Western European countries reporting age-standardised incidence rates per 100000 population, averaging 29.5 for men and 23.2 for women. ${ }^{[1]}$ This is in sharp contrast to subSaharan African countries that report much lower age-standardised incidence rates, ranging from 6.3 in men and 2.7 in women in Mozambique, to the highest rates, i.e. 15.6 in men and 9.5 in women in South Africa (SA). ${ }^{[1,3]}$

Although there are reasonably adequate reports on the epidemiology of CRC in sub-Saharan Africa, data on the prevalence of adenomas are sparse. In an analysis of 91 surgical resections for CRC between 1996 and 1997 in Pretoria, SA (white: $n=48$; black African: $n=43$ ), adenomas were found in $25 \%$ of whites and $20 \%$ of black Africans ${ }^{[4]}$ A retrospective review in 1999 reported that of 172 CRC resections in black Africans on the Witwatersrand, SA, 5\% had synchronous adenomas ${ }^{[5]}$ Apart from the small numbers, these studies were in patients at high risk of adenomas by virtue of them already having invasive CRC, and were based on segmental colonic resections, rather than removal of the entire colon. Therefore, the figures cannot be generalised to the average-risk population. While colonoscopy-based studies would give more accurate data, very few have been performed. In a review of 460 colonoscopies in Zimbabwe, mainly in symptomatic patients, polyps were found in $5 \%{ }^{[6]}$ Similarly, in a review of 415 colonoscopies in Nigeria, adenomas were present in $7 \%$ of patients. ${ }^{[7]}$ In contrast, the prevalence of adenomas in asymptomatic individuals in the USA at screening colonoscopy was as high as $37 \%$, and the prevalence of advanced adenomas was $6-8 \%{ }^{[8,9]}$ Data in sub-Saharan Africa are further limited by low numbers and a lack of systematic histological examination of the polyps.

Recent data from Zimbabwe show that the incidence of CRC is increasing, possibly owing to a combination of improved diagnosis and a true increase in new cases. ${ }^{[10,11]}$ These increases have also been reported in several countries across Africa, and SA should be no exception. There is limited knowledge on the pattern of neoplastic 
polyps in SA and the sub-Saharan African region, which could guide prevention strategies and help to estimate the trajectory of CRC. Therefore, we reviewed data of patients with an average risk of CRC using a prospective colonoscopy registry at a tertiary hospital in the Cape Metropole, and estimated the adenoma detection rate (ADR) for clinicians to use as a benchmark in SA and the rest of Africa. Furthermore, we comprehensively described the pathological patterns of colorectal polyps in this population.

\section{Methods}

A cross-sectional study was conducted at the Gastrointestinal Clinic at Groote Schuur Hospital, a tertiary institution in Cape Town, SA. Data of all adult patients ( $>18$ years old), who had undergone a colonoscopy between August 2014 and February 2017, were retrieved from the prospective endoscopy registry. Cases of inflammatory bowel disease, flexible sigmoidoscopies and incomplete colonoscopies due to inadequate bowel preparation were excluded from the analysis. Repeat colonoscopies performed within 6 months of the initial procedure were considered as a single procedure. Data on age, gender, ethnicity, number of polyps, morphology, size and location were extracted from the database. The ADR was calculated as the number of patients with at least one adenoma divided by the number of colonoscopies performed.

Bowel preparation was routinely assessed segmentally, and graded and recorded as good, adequate or poor (but proceeded with colonoscopy), and caecal intubation rate was automatically recorded. Data on histological findings were obtained from the National Health Laboratory Service (NHLS). Data on the histological subtype and degree of dysplasia were extracted from the narrative reports and merged with the endoscopic dataset, using the patients' unique hospital numbers.

Continuous data were summarised using mean values with standard deviations (SDs), or median values with interquartile range (IQR), as appropriate. The various proportions were summarised using percentages and confidence intervals (CIs). The $\chi^{2}$ test or Fisher's exact test were employed to compare categorical data, and the student $t$-test was used for continuous variables. All the analyses were carried out using Stata 14 (Stata Corp., USA).

\section{Ethical approval}

Ethical approval was obtained from the University of Cape Town Human Research
Ethics Committee (ref. no. HREC REF 617/2018).

\section{Results}

Of 1334 colonoscopies in the database over the study period, 342 were performed in patients at increased risk of developing CRC; these were excluded from the analysis.

Fig. 1 shows how the cohort was derived and the histological findings.

Of the 992 colonoscopies analysed, $70 \%$ were performed in patients $>50$ years of age, $76 \%$ were in patients of mixed race, $12 \%$ were in black Africans and $11 \%$ were in whites. Rectal bleeding was the most common indication for a colonoscopy, followed by abdominal pain and change in bowel habit.

Colorectal polyps were identified in 172 of the 992 patients (17.3\%), of whom 119 (12\%) had confirmed adenomas.
Table 1 compares the baseline clinical and demographic features of the 119 individuals with adenomas with those of individuals without adenomas. Generally, patients with adenomas were significantly older than those with no adenomas (61.5 (12.9) v. 56.3 (17.4) years; $p<0.002$ ), and $82 \%$ of those with adenomas were $>50$ years of age. The result of bowel preparation was good in $54 \%$, adequate in $28 \%$ and poor in $18 \%$, although a complete colonoscopy was performed. The quality of bowel preparation and the caecal intubation rate were similar between the two groups.

A total of 246 polyps were visualised, and $42 \%$ were $<5 \mathrm{~mm}$ in size, with $72 \%$ sessile. Two hundred and six were removed, and on histological examination, 27 had normal mucosa and 26 were hyperplastic. Adenomas $(n=148)$ were detected in 119 patients. Seven patients had 2 adenomas, 3 had 3 adenomas and 1 had 6 adenomas.

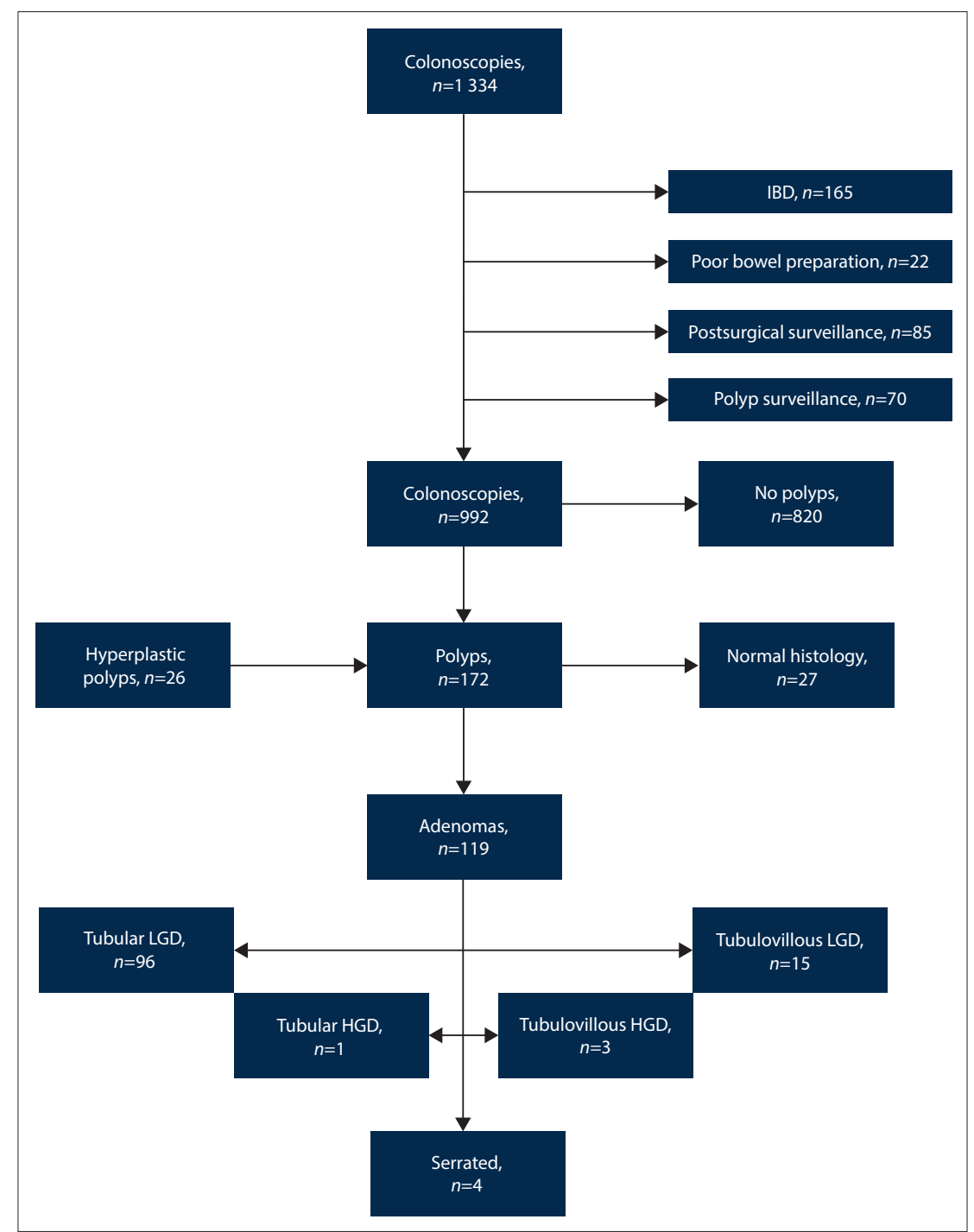

Fig. 1. Consort diagram showing selection criteria and histological findings. (IBD = inflammatory bowel disease; $L G D=$ low-grade dysplasia; $H G D=$ high-grade dysplasia.) 
The most advanced histology for these adenomas per patient were: tubular with low-grade dysplasia $(n=96)$, tubular with high-grade dysplasia $(n=1)$, tubulovillous with low-grade dysplasia $(n=15)$, tubulovillous with high-grade dysplasia $(n=3)$ and serrated $(n=4)$ (Fig. 1).

The anatomical distribution of the adenomas is shown in Table 2. Approximately $51 \%$ of the adenomas were in the proximal colon, and $22 \%$ were located in the rectum. The ADR was $12 \%(119 / 992)$ in all age groups, and $14 \%$ (97/693) in those $>50$ years of age, with equal gender distribution. The ADR by ethnicity was as follows: mixed race (13\%), white (18\%), Asian (18\%) and black African (5\%).

\begin{tabular}{|c|c|c|}
\hline Variables & $\begin{array}{l}\text { Colonoscopies in } \\
\text { patients without } \\
\text { adenomas } \\
(N=873), n(\%)^{*}\end{array}$ & $\begin{array}{l}\text { Colonoscopies } \\
\text { in patients } \\
\text { with adenomas } \\
(N=119), n(\%)^{*}\end{array}$ \\
\hline \multicolumn{3}{|l|}{ Gender } \\
\hline Male & $325(37)$ & $44(37)$ \\
\hline Female & $548(63)$ & $75(63)$ \\
\hline \multicolumn{3}{|l|}{ Ethnicity } \\
\hline Mixed race & $662(76)$ & $95(80)$ \\
\hline Black & $113(14)$ & $6(5)$ \\
\hline White & $87(10)$ & $16(13)$ \\
\hline Asian & $11(2)$ & $2(2)$ \\
\hline Mean age (SD), years & $56.3(17.4)$ & $61.5(12.9)$ \\
\hline \multicolumn{3}{|l|}{ Age categories, years } \\
\hline$\geq 50$ & $596(70)$ & $97(82)$ \\
\hline$<50$ & $277(30)$ & $22(18)$ \\
\hline Weight loss & $165(14)$ & $22(16)$ \\
\hline Rectal bleeding & $203(18)$ & 27 (19) \\
\hline Diarrhoea & $128(11)$ & $7(5)$ \\
\hline Constipation & $180(16)$ & $24(17)$ \\
\hline Asymptomatic & $49(4)$ & $5(4)$ \\
\hline Anaemia & $160(14)$ & $19(14)$ \\
\hline Alteration in bowel habit & $65(6)$ & $10(7)$ \\
\hline Abdominal pain & $198(17)$ & $25(18)$ \\
\hline \multicolumn{3}{|l|}{ Bowel preparation } \\
\hline Good & 409 (47) & $64(54)$ \\
\hline Adequate & $293(34)$ & $33(28)$ \\
\hline Poor & $171(20)$ & $22(18)$ \\
\hline Caecal intubation rate & $784(90)$ & $107(90)$ \\
\hline
\end{tabular}

\section{Discussion}

We describe the findings of 992 colonoscopies performed at Groote Schuur Hospital in patients at average risk of developing CRC. The aim was to estimate the frequency and pathological spectrum of the adenomas. The overall ADR was $12 \%$ in all age groups, which did not vary between men and women. In those $>50$ years of age, the ADR was $14 \%$. This percentage is lower than the recommended ADR of $>25 \%$ in men, according to North American and Western European guidelines, but closer to the target of $>15 \%$ in women. ${ }^{[12]}$ Interestingly, the rate of advanced adenomas in our study (6\%) in average-risk symptomatic patients was comparable with rates of $6-8 \%$ in the asymptomatic screening population in the USA ${ }^{[8,9]}$ However, it is unclear whether our presumed average-risk population, originating from a hospital setting, would be comparable with the asymptomatic screening population in the USA. Nonetheless, our findings represent the first comprehensive report on adenomas in an SA tertiary state institution.

SA is a diverse, multicultural country with marked provincial variation in the ethnic proportions and wide variations in CRC risk based on ethnicity. ${ }^{[13]}$ SA's population is estimated at 58.8 million, of which black Africans constitute $81 \%$, mixed race $9 \%$, whites $8 \%$ and Asians 2\%. In contrast, the population in our catchment area, the Cape Town Metropole, was 3.7 million in 2012, with $42 \%$ being of mixed race, $39 \%$ black African, $15.7 \%$ white and $1.4 \%$ Asian. ${ }^{[14]}$ Our findings reflect the differences in CRC risk between the diverse ethnic groups in our population. The lowest rate of adenomas (5\%) was in black African patients, which is similar to rates in Nigeria and Zimbabwe ${ }^{[6,7]}$ However, the frequency of adenomas was much higher in patients of mixed race and white patients, reflecting a higher risk of CRC in these populations. There was a predominance of adenomas in the proximal colon, which is similar to that in the traditional high-incidence countries, and may reflect the impact of obesity and lifestyle-related factors. ${ }^{[15,16]}$ Colorectal neoplasia has a stronger association with lifestyle when it occurs in the proximal colon compared with the distal colon. ${ }^{[17-20]}$ The higher frequency of colonic compared with rectal adenomas is similar to a previous study of CRC in the Northern Cape, in which $64 \%$ of adenomas were located in the colon - not in the rectum. ${ }^{[21]}$ However, CRC in this population is rather enriched with Lynch syndrome, which is known to have a predilection for the proximal colon. Nonetheless, our study excluded patients with a high risk of premalignant lesions; therefore, our results are probably a true reflection of the distribution of adenomas in this population.

\section{Study limitations}

Several factors contributed to the ADR at colonoscopy in this study. Key among these is the efficacy of bowel preparation, which was poor in $18 \%$ of the participants. This does not meet the key performance

Table 2. Anatomical distribution of the histological types of adenomas

\begin{tabular}{|c|c|c|c|c|c|}
\hline \multirow[b]{2}{*}{ Polyp site } & \multicolumn{5}{|c|}{ Polyp histology } \\
\hline & TALGD & TAHGD & TVALGD & TVAHGD & Serrated adenoma \\
\hline Caecum & 15 & 1 & 1 & 0 & 0 \\
\hline Ascending colon & 20 & 0 & 2 & 1 & 0 \\
\hline Transverse colon & 19 & 0 & 2 & 0 & 2 \\
\hline Descending colon & 12 & 0 & 3 & 0 & 2 \\
\hline Sigmoid colon & 16 & 0 & 2 & 0 & 0 \\
\hline Rectum & 14 & 0 & 5 & 2 & 0 \\
\hline Total & 96 & 1 & 15 & 3 & 4 \\
\hline
\end{tabular}


indicator in international guidelines, which aims for at most 5 - 15\%. ${ }^{[12,22]}$ Therefore, it is possible that there may be under-detection of polyps in our practice. It could be argued that the outcomes of our colonoscopies were affected by the varying levels of experience of the clinicians, who ranged from novice gastroenterology and surgical trainees to senior consultant gastroenterologists. However, our training is modelled on the UK Joint Advisory Group (JAG) Endoscopy Training System (JETS) principles, and trainees are usually supervised by a gastroenterologist or colorectal surgeon. ${ }^{[23]}$ Therefore, it is unlikely that the inclusion of data from trainees had a negative effect on the ADR. Moreover, evidence from an earlier study using this registry showed that the ADR of mature trainees was as good as that of consultants, suggesting that the effect is negligible. ${ }^{[24]}$ Another potential limitation is selection bias inherent in data obtained from a single tertiary hospital. To our credit, the caecal intubation rate of $90 \%$ was in keeping with both UK and US recommendations for colonoscopy in symptomatic patients, who constituted the majority of our cohort. ${ }^{[12,25]}$ However, withdrawal time was not documented.

\section{Conclusions}

Despite these limitations, our study represents the first attempt at determining the ADR in SA, and is the largest dataset describing the pathological spectrum of polyps. It provides a benchmark for clinicians who perform diagnostic and screening colonoscopies, both in the state and in the private sector. This should be individualised, given the differences in adenoma frequency between different population groups. Furthermore, these data reaffirm the higher risk of CRC in mixed race and white patients. The threshold for opportunistic screening in these groups should be low, while population-based screening may be merited. Whereas the low frequency of adenomas in the black population suggests a relatively low incidence of CRC, a registry of this nature can act as an early warning system of changes in CRC risk. Finally, these findings should not detract from the need to provide timely colonoscopy in all symptomatic patients, regardless of the perception of CRC risk.

Declaration. The research for this study was done in partial fulfilment of the requirements for JK's MMed (Internal Medicine) degree at the University of Cape Town.

Acknowledgements. None.

Author contributions. JK developed the study protocol, collected and analysed the data and wrote the manuscript. SRT, MS and LK contributed to the study design, data analysis and reviewing and editing of the manuscript.
Funding. The Faculty of Health Sciences, University of Cape Town, funded the publication.

Conflicts of interest. None.

1. Ferlay J, Colombet M, Soerjomataram I, et al. Estimating the global cancer incidence and mortality in 2018: GLOBOCAN sources and methods. Int J Cancer 2018;144(8):1941-1953. https://doi, org $/ 10.1002 /$ ijc. 31937

2. Fearon ER, Vogelstein B. A genetic model for colorectal tumorigenesis. Cell 1990;61(5):759-767. https://doi.org/10.1016/0092-8674(90)90186-1

3. Lorenzoni C, Vilajeliu A, Carrilho C, et al. Trends in cancer incidence in Maputo, Mozambique, 1991 2008. PLoS ONE 2015;10(6):e0130469. https://doi.org/10.1371/journal.pone.0130469

4. Angelo N, Dreyer L. Colorectal cancer - a new threat to black patients? A retrospective analysis of colorectal carcinoma received by the Institute for Pathology, University of Pretoria. S Afr Med J 2001;91(8):689-692.

5. Boytchev H, Marcovic S, Oettle G. The characteristics of large bowel cancer in the low-risk black population of the Witwatersrand. J R Coll Surg Edinb 1999;44(6):366-370

6. Katsidzira L, Gangaidzo IT, Mapingure MP, Mateng JA. Retrospective study of colorectal cancer in Zimbabwe: Colonoscopic and clinical correlates. World J Gastroenterol 2015;21(8):2374-2380. https:// doi.org/10.3748/wjg.v21.i8.2374

7. Alatise OI, Arigbabu AO, Agbakwuru AE, et al. Polyp prevalence at colonoscopy among Nigerians: A prospective observational study. Niger J Clin Pract 2014;17(6):756-762. https://doi.org/10.4103/11193077.144391

8. Lieberman DA, Weiss DG, Bond JH, et al. Use of colonoscopy to screen asymptomatic adults for colorectal cancer. N Engl J Med 2000;343(3):162-168. https://doi.org/10.1056/nejm200007203430301 . Lieberman DA, Holub JL, Moravec MD, Eisen GM, Peters D, Morris CD. Prevalence of colon polyps detected by colonoscopy screening in asymptomatic black and white patients. JAMA 2008;300(12):1417-1422. https://doi.org/10.1001/jama.300.12.1417

10. Chokunonga E, Borok M, Chirenje Z, Nyakabau A, Parkin D. Trends in the incidence of cancer in the black population of Harare, Zimbabwe 1991 - 2010. Int J Cancer 2013;133(3):721-729. https://doi. org $/ 10.1002 /$ ijc. 28063

11. Katsidzira L, Chokunonga E, Gangaidzo IT, et al. The incidence and histopathological characteristics of colorectal cancer in a population based cancer registry in Zimbabwe. Cancer Epidemiol 2016;44:96-100. https://doi.org/10.1016/j.canep.2016.08.001

12. Rex DK, Petrini JL, Baron TH, et al. Quality indicators for colonoscopy. Am J Gastroenterol 2006;101(4):873-885. https://doi.org/10.1111/j.1572-0241.2006.00673.x

13. Parkin DM, Bray F, Ferlay J, Jemal A. Cancer in Africa 2012. Cancer epidemiology biomarkers and prevention. Am Ass Cancer Res 2014;23(6):953-966. https://doi.org/10.1158/1055-9965.epi-14-0281 Statistics South Africa. Census 2011. Provincial profile: Western Cape. www.statssa.gov.za (accessed 21 October 2020).

15. Yuhara H, Steinmaus C, Cohen SE, Corley DA, Tei Y, Buffler PA. Is diabetes mellitus an independent risk factor for colon cancer and rectal cancer? Am J Gastroenterol 2011;106(11):1911-1921. https:// doi.org/10.1038/ajg.2011.301

16. Renehan AG, Tyson M, Egger M, Heller RF, Zwahlen M. Body-mass index and incidence of cancer: A systematic review and meta-analysis of prospective observational studies. Lancet 2008;371(9612):569-578. https://doi.org/10.1016/S0140-6736(08)60269-X

17. Cheng L, Eng C, Nieman LZ, Kapadia AS, Du XL. Trends in colorectal cancer incidence by anatomic site and disease stage in the United States from 1976 to 2005. Am J Clin Oncol 2011;34(6):573-580. https://doi.org/10.1097/coc.0b013e3181fe4led

18. Chauvenet M, Cottet V, Lepage C, et al. Trends in colorectal cancer incidence: A period and birth-cohort analysis in a well-defined French population. BMC Cancer 2011;11:282. https://doi. org/10.1186/1471-2407-11-282

9. Takada H, Ohsawa T, Iwamoto S, et al. Changing site distribution of colorectal cancer in Japan. Dis Colon Rectum 2002;45(9):1249-1254. https://doi.org/10.1007/s10350-004-6400-0

20. Corley DA, Jensen CD, Marks AR, et al. Variation of adenoma prevalence by age, sex, race, and colon location in a large population: Implications for screening and quality programs. Clin Gastroenterol Hepatol 2013;11(2):172-180. https://doi.org/10.1016/j.cgh.2012.09.010

21. Wentink M, Rakers M, Stupart D, et al. Incidence and histological features of colorectal cancer in the Northern Cape Province, South Africa. S Afr J Surg 2010;48(4):109-113.

22. Rex DK, Schoenfeld PS, Cohen J, et al. Quality indicators for colonoscopy. Am J Gastroenterol 2015;110(1):72-90. https://doi.org/10.1038/ajg.2014.385

23. Siau K, Green JT, Hawkes ND, et al. Impact of the Joint Advisory Group on Gastrointestinal Endoscopy (JAG) on endoscopy services in the UK and beyond. Frontline Gastroenterol 2018;10(2):93-106. https://doi.org/10.1136/flgastro-2018-100969

24. Nel R. Comparison of the full-spectrum endoscopy, magnetic endoscopic imaging and standard forward viewing endoscopy. S Afr Gastroenterol Rev 2016;4(2):46.

25. Rees CJ, Gibson ST, Rutter MD, et al. UK key performance indicators and quality assurance standards for colonoscopy. Gut 2016;65(12):1923-1929. https://doi.org/10.1136/gutjnl-2016-312044

Accepted 17 July 2020 